\title{
A Conversation with Abbey
}

Michael Sakamoto, University of lowa

Angella Betina Carlos ("Abbey"), University of lowa

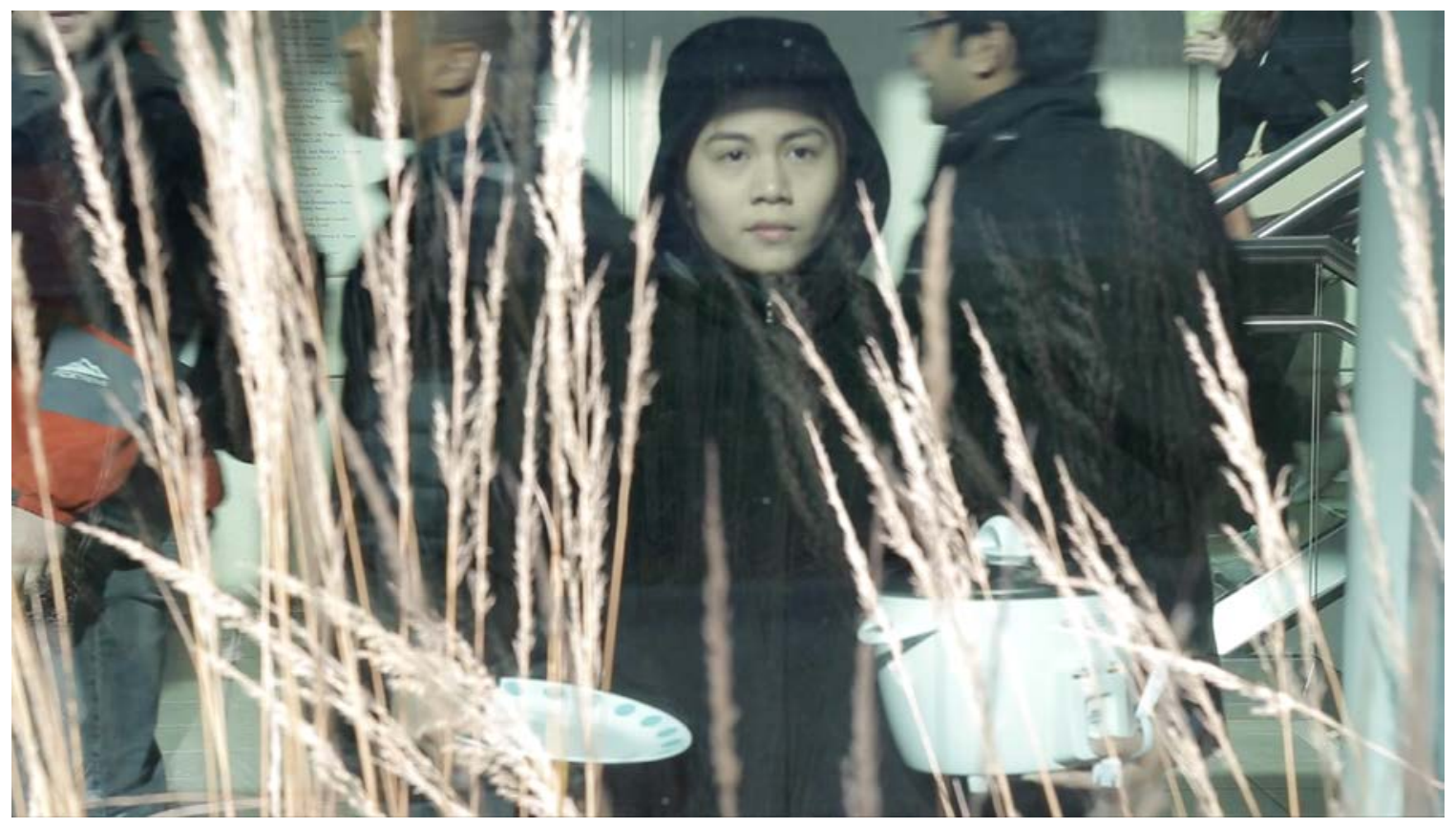

Screenshot from Abbey (2016). Dir. Michael Sakamoto. Chor. and perf. Angella Betina Carlos. View the film at https://vimeo.com/155411637

Abbey is a six-minute dancefilm produced in 2016, directed, photographed, and edited by Michael Sakamoto, and choreographed and performed by Angella Betina Carlos, who goes by her nickname, Abbey. The film was shot at University of lowa, where Sakamoto is an Assistant Professor in Dance and Carlos was an MFA student. The following are excerpts from a conversation between the filmmaker and performer.

By turns reflective and visceral, Abbey depicts the interior life of a sheltered young Filipina alone in a university dance setting in middle America. Sakamoto and Carlos collaborated in an effort to bear witness as well as portray Carlos's sense of tenuous liminality as a stranger in a strange land. Issues of normativity around social roles in Asian and American contexts, gender and physical expression, and the mediating power of language and its relationship to postcolonial identity were all implicit and considered in developing Abbey's onscreen character. As filmmaker and subject, Sakamoto and Carlos also engage in implicit dialogue as gendered subalterns, the gaze of Sakamoto's technologizing camera and digital edit attempting to create and hold The International Journal of Screendance 9 (2018). 
space for Carlos's spontaneous and multiple corporealities of transnational Asian female identity.

MICHAEL: Who is your character in the film?

ABBEY: Me. (Laughs). It's two sides of me. One is the dancer me, who wants to be seen, who wants to stand out and show herself, and the other is the everyday real me, who just wants to blend in and not be seen. Who's really shy, insecure, and all these negative self-images.

MICHAEL: Do you see those two sides as distinct?

ABBEY: I think I do. I guess when I'm dancing in class, it's this weird mix of I want you to see me, but at the same time, I don't want you to point me out. I want you to acknowledge it without highlighting me. It's different (in daily life) when I'm not in a studio, and I just want to hide, not interact.

MICHAEL: Do you think that's a cultural thing?

ABBEY: It could be. Back home, when you're in class and dancing, you have to respect your teacher, you can't talk back, be too opinionated, or too emotional. You have to be respectful and agree. If you disagree, just save it for yourself.

MICHAEL: I was probably interested in doing this project because, even as a fourth generation Asian-American, I grew up with a bit of that same pressure to conform. How do you think any of that played into your character in the film?

ABBEY: I think it's the part where I improv. I think it represents that way of freedom and vulnerability and confidence that I'm finding now, not just as a dancer, but as a person. Back home, people are more conservative because we're Catholic, and there are expectations of what you should be as a woman. You're the good girl, you're the person who always gets good grades, you're the great dancer. So I feel like here, starting fresh, where no one knows me, I can change, make something different out of myself.

MICHAEL: We shot the film only three months after you arrived.

ABBEY: Watching it, I was like, whoa, my accent was different. Even my movement was fresh from what I was doing back home.

MICHAEL: Back then, two years ago, we created a character that was influenced by a culture clash of you coming from Filipino, Asian, and Southeast Asian background, language, culture, everything, coming to middle America. Totally different people, culture, climate, and, to a certain extent, different language, even though you speak English. 
ABBEY: Now, sometimes it feels weird when I speak Tagalog. I went home this summer, and they asked me to teach at my old university, and I could not teach in Filipino. I was like, I'm so sorry, but I'm so used to teaching in English now, that I have to. Whenever I would try to say something in Filipino, I had this weird accent, and I could not articulate myself. I think I rewired my brain.

MICHAEL: I think I was conscious that you were experiencing a really personal process of internalizing intercultural tension. That's why I shot your character mostly with fairly gentle camerawork, except for the first shot, of course, where I do a quick pan-zoom. That's the one insistent moment in the whole film because I want the viewer to know we're entering your world, one that belongs to you.

Looking back, though, does the depiction of that culture clash still resonate with you? Is it an accurate portrayal of what you were feeling, or what you still feel?

ABBEY: Of course, it's a blown up version, but I think it still holds true. I still feel like I don't totally fit in here and am more at home in the Philippines. It's still more the way I think. Here in the States, those differences already filter out some aspects of myself. Language alone changes who I am here. I wouldn't say I'm Americanized, but I'm not as conservative as before, or I feel more neutral about some things back home. I'm becoming more open.

MICHAEL: Do you feel stuck in between?

ABBEY: I'm at this point where I'm a little confused. Compared to when we did the film, I definitely feel more stuck in the middle.

MICHAEL: Maybe you're even more that character?

ABBEY: Probably, yeah! I feel like I'm in purgatory. Kind of belonging here, but not fully.

MICHAEL: What about the difference for you between dancing on stage and for the camera?

ABBEY: With a camera, there's no one there, and you don't get that audience energy, but it's also nice because it's not judgmental. It can't think. It's not going to judge me for the way I perform and look. And for this film, I think I was comfortable showing those things because I knew there are almost no Filipinos here. No one knows what I'm saying. They get to see part of my culture, but at the same time, no one's going to understand me, and that's fine. I was thinking, "This is healing to me." I do want them to see it, but I do like the fact that I'm the only one who truly knows what it is and understands what it is.

MICHAEL: When we were filming, did it matter that I was Asian-American? 
ABBEY: It made it easier for me to open up and be okay with that difference. If I were working with a white male or female, to show those things, I don't know if I would be comfortable. Because I was trying to fit in, showing that side would have been not part of the plan. It's because you understand and you're not just using the stereotype of what an Asian or Filipino is. It wasn't just, "Oh, you love rice, so let's use a rice cooker." There was a purpose to it. It wasn't superficial.

MICHAEL:Yeah, I wanted to eat the rice too.

(Both laugh.)

MICHAEL: What are you curious about looking back at the project?

ABBEY: How did you process my performance? How was it to hear and see someone speaking a different language?

MICHAEL: For me, it's really important to let both the person and character speak for themselves and from themselves. I want to depict as much as I can how they experience everyday reality. Because we created a character that's lost in America, I wanted to show that sense of isolation in a very simple way, not too subtle and not too didactic.

But also, where does she find her agency, her sense of empowerment? And that's what we really build up to, when she starts dancing. So when you were speaking Tagalog, I just put myself in the position of your average American. Like, okay, this is who she is. I don't understand a word. I'm just trying to hold the space for her, or just be with her, not only as a filmmaker, but as an audience member as well.

I hope the average American viewer would bring a sense of acceptance to it. I always ask my audience to meet us halfway. So yeah, it's a question, why didn't you translate or provide subtitles, but it's also the question, why do you need it to be translated? This is who she is. What does it mean that she's here and has this experience? Why should she have to translate? It's like my other show, Soil, a devised, autobiographical performance with dancers from Thailand, Cambodia, and Vietnam, and all of whom live part or most of their lives in America. Soil also has a couple untranslated scenes on purpose because we want the audience to reflect on what the character-performers are going through mentally, emotionally, and physically, when they're in a space where they know, "Nobody understands me right now, but I do, and what I'm saying matters to me."

ABBEY: Was there a noticeable difference between when I was speaking Tagalog in the film, like in my body language, my personality, my character, and when I speak in English?

MICHAEL: When you were speaking Tagalog when we were shooting outside, you were like a closed-off shell. It felt very intimate. You were speaking to yourself. And then 
there's the scene at the end in your dance outfit. It's who you are on the inside. You're physically relaxed, just eating on the floor, and your body language is loose. I was happy for that as a filmmaker. Earlier in the film, though, it's a very black and white depiction. We set it up where when you walk into a ballet class, you're not a part of that environment initially. You're not able to be you until you somehow move in your own way or from your own motivations.

ABBEY: I think dance would be the one thing that brings me together, where I'm truly myself. I don't feel there's a gap between what I was doing before and now. I think it meshed and melted into each other. I for sure have absorbed a style here, but the influences from back home are still present in my body.

\section{Biographies}

Michael Sakamoto is an interdisciplinary artist and scholar active in dance, theatre, performance, media, and photography whose works have been presented in 14 countries worldwide. He is currently touring three full-length, dance theater performances: Flash, a butoh/hip-hop duet with Rennie Harris, Soil, a trio featuring dancers from Cambodia, Vietnam, and Thailand, and blind spot, a full length work-inprogress in collaboration with digital composer-musician, Christopher Jette. Michael's photography has been exhibited in museums and galleries in Los Angeles, Bangkok, and Chiang Mai. He regularly publishes scholarly and creative articles and book chapters, and his book project, An Empty Room: Butoh Performance and the Social Body in Crisis, is under contract with Wesleyan University Press. Michael is Assistant Professor in Dance At University of lowa and holds an MFA and PhD from the UCLA Department of World Arts and Cultures/Dance.

\section{Email: michaelsakamoto1@gmail.com \\ Website: www.michaelsakamoto.org.}

Angella Betina Carlos ("Abbey") is a Filipina contemporary dance artist with a passion for performing and teaching. She has been given featured roles in multiple performances and has danced in competitions and festivals in the Philippines, around Asia, and in the United States. Her awards include the Luva Adameit Award (Special Award for a Female Dancer) during the 1st Cultural Center of the Philippines National Ballet Competition, as well as national and international scholarships to study and train in dance. Abbey graduated cum laude with a Bachelor in Music, Major in Dance degree from the University of the Philippines Diliman, and was a member of the resident dance group, the UP Dance Company, for six years. Abbey recently completed an MFA in Dance with a focus on performance at the University of lowa.

Email: angellabetinacarlos@gmail.com 